\title{
Vehicular Quality Biomethane Production from Biogas by Using an Automated Water Scrubbing System
}

\author{
R. Chandra, ${ }^{1}$ V. K. Vijay, ${ }^{2}$ and P. M. V. Subbarao ${ }^{3}$ \\ ${ }^{1}$ Department of Farm Power \& Machinery, College of Agricultural Engineering \& Post Harvest Technology, \\ Central Agricultural University, Ranipool, Gangtok, Sikkim 737 135, India \\ ${ }^{2}$ Centre for Rural Development \& Technology, Indian Institute of Technology Delhi, Hauz Khas, New Delhi 110 016, India \\ ${ }^{3}$ Department of Mechanical Engineering, Indian Institute of Technology Delhi, Hauz Khas, New Delhi 110 016, India
}

Correspondence should be addressed to R. Chandra,ram.chandra6dec@gmail.com

Received 3 April 2012; Accepted 2 May 2012

Academic Editors: R. S. Adhikari and S. S. Kalligeros

Copyright ( $) 2012$ R. Chandra et al. This is an open access article distributed under the Creative Commons Attribution License, which permits unrestricted use, distribution, and reproduction in any medium, provided the original work is properly cited.

This paper presents the results of an automated water scrubbing system used for enrichment of methane content in the biogas, to produce vehicular grade biomethane fuel. Incorporation of automatic control systems for precisely regulating the water level and maintaining constant operating pressure in the packed bed absorption column of water scrubbing system resulted in steadystate operation of the scrubbing system and a consistent supply of methane-enriched biogas from the gas outlet. The improved automated water scrubbing system was found to enrich $97 \%$ methane at an operating column pressure of $1.0 \mathrm{MPa}$ with $2.5 \mathrm{~m}^{3} / \mathrm{h}$ biogas in-flow rate and $2.0 \mathrm{~m}^{3} / \mathrm{h}$ water in-flow rate into the scrubbing column unit.

\section{Introduction}

The future energy security concerns along with the increasing concentration of the carbon dioxide and methane greenhouse gases emission problems have strengthened the interest in development and utilization of alternative, nonpetroleum-based renewable sources of energy $[1,2]$. Biogas is an important renewable fuel among the various biomassderived renewable fuel, particularly for rural areas. It is an environment friendly, clean, cheap, and versatile fuel. In fact, all over the world, biogas has been extensively used for heating purposes and/or electricity generation [3].

The presence of high concentration of carbon dioxide in biogas lowers the energy content per unit mass/volume and limits its utility to only low quality energy applications. The presence of carbon dioxide in biogas is undesirable to use as a vehicular fuel because it lowers the power output from the engine and it occupies additional space in the storage cylinders. Hence, it reduces the refilling range of the vehicle. Furthermore, the presence of carbon dioxide in biogas can cause problem of freezing at valves and metering points. Therefore, removal of carbon dioxide from the biogas may enhance the utility of biogas for wider range of applications.
With available technologies, it is economically possible to enrich methane content of biogas up to the natural gas level. The methane enrichment of biogas to biomethane quality and feeding into the natural gas grid/compression in cylinders is an effective way of integrating the biogas into the energy sector. Thus, it can be successfully used as substitute of natural gas and transportation fuel, combined heat and power, and electricity generation applications $[4,5]$.

In this present study/experiment, a water scrubbing system for methane enrichment in biogas was modified and automated using electronic control system. The electronic control system runs the system under steady state and maintains a consistent methane quality in purified gas outlet stream, in order to produce vehicular quality biomethane from biogas.

\section{Processes of Methane Enrichment in Biogas}

Methane enrichment in biogas can be carried out by various processes. Table 1 presents the different methods/processes with their comparatives in term of various operational parameters. 
TABLE 1: Comparison of different methods of methane enrichment in biogas.

\begin{tabular}{|c|c|c|c|}
\hline Sl. No. & Method & Advantages & Disadvantages \\
\hline (1) & Absorption in water & $\begin{array}{l}\text { One of the easiest and cheapest methods } \\
\text { for } \mathrm{CO}_{2} \text { removal. Recommended for rural } \\
\text { application. }\end{array}$ & $\begin{array}{l}\text { Water pumping load is high and some loss } \\
\text { of methane with washing water. }\end{array}$ \\
\hline (2) & Absorption by chemicals & $\begin{array}{l}\text { The chemical absorbents are more effi- } \\
\text { cient in low pressure and can remove } \mathrm{CO}_{2} \\
\text { to low partial pressures in treated gas. }\end{array}$ & $\begin{array}{l}\text { Regeneration of the solvent requires a rel- } \\
\text { atively high energy input. Disposal of by- } \\
\text { product formed due to chemical reactions } \\
\text { is a problem. }\end{array}$ \\
\hline (3) & Pressure swing adsorption & $\begin{array}{l}\text { By proper choice of the adsorbent, this } \\
\text { process can remove } \mathrm{CO}_{2}, \mathrm{H}_{2} \mathrm{~S} \text {, moisture } \\
\text { and other impurities. }\end{array}$ & $\begin{array}{l}\text { Adsorption is accomplished at high tem- } \\
\text { perature and pressure. Regeneration is } \\
\text { carried out by vacuum. It is a costly } \\
\text { process. }\end{array}$ \\
\hline (4) & Membrane separation & $\begin{array}{l}\text { Modular in nature and separate } \mathrm{CO}_{2} \text { and } \\
\mathrm{CH}_{4} \text { effectively. }\end{array}$ & $\begin{array}{l}\text { High pressure requirement. The process- } \\
\text { ing cost is also high. }\end{array}$ \\
\hline (5) & Cryogenic separation & $\begin{array}{l}\text { Allows recovery of pure component in the } \\
\text { form of liquid, which can be transported } \\
\text { conveniently }\end{array}$ & $\begin{array}{l}\text { High cost involved makes it impractical } \\
\text { for biogas applications. }\end{array}$ \\
\hline (6) & Chemical conversion & Extremely high purity in the product gas. & $\begin{array}{l}\text { Process is extremely expensive and is } \\
\text { not warranted in most cases of biogas } \\
\text { applications. }\end{array}$ \\
\hline
\end{tabular}

2.1. Water Scrubbing of Biogas. Carbon dioxide has higher solubility in water than methane. Therefore, more carbon dioxide is dissolved in water than methane, particularly at lower temperature. In the water scrubbing process, carbon dioxide dissolves in the water, while the methane concentration in the gas phase increases. The gas leaving the scrubber has, therefore, an increased concentration of methane. Apart from carbon dioxide, water is capable of removing other impurities such as hydrogen sulfide, ammonia, hydrogen phosphide, chlorinated hydrocarbons, and others. The water leaving the absorption column contains dissolved gases mainly carbon dioxide with very little amount of methane and others. The operation of water scrubbing system is highly dependent on the solubility of carbon dioxide at particular temperature and pressure in water to form dilute carbonic acid

$$
\mathrm{CO}_{2}+\mathrm{H}_{2} \mathrm{O}=\mathrm{H}_{2} \mathrm{CO}_{3}
$$

The compressed raw biogas is fed to a packed bed absorption column from the bottom of the scrubber, and pressurized water is sprayed from the top (counter-current flow of biogas and water). This process is one of simplest and cheapest method of methane enrichment in biogas/landfill gas for small as well as larger scales. Another advantage of water scrubbing system over other processes is that the outcoming water containing dissolved carbon dioxide and other impurities from the scrubbing column is fairly easy to dispose. However, in other processes the chemicals used require special handling and disposal in order of environmental safety and health hazards [6-9].

\section{Materials and Methods}

The water-scrubbing-based methane enrichment in biogas and further compression/bottling into CNG cylinder system was designed and developed at Indian Institute of Technology Delhi, India, for enhancing the utility of biogas application that is, vehicular use. The system consists a water scrubbing column and methane-enriched biogas compression system. Figure 1 shows the schematic diagram of complete system. The lack of automation in the developed system had resulted into inconsistent methane quality in purified gas outlet stream due to continuous fluctuation of water level, inlet biogas flow rate, and thereby operating pressure of scrubbing column. Therefore, in order to get a consistent methane-quality-enriched biogas, the existing water scrubbing system was automated by using electronic control/instrumentations to run the system under steady state. Figure 2 shows the automated water scrubbing system. Brief descriptions of the incorporated controls were as follows.

3.1. Automatic Pressure Controller at Inlet of Scrubber. A pressure regulating valve was fitted between the raw biogas storage vessel and input biogas line to the water-scrubbing column unit. The pressure regulating valve maintained almost constant pressure at the inlet of the water-scrubbing column unit irrespective of high pressure inside raw biogas storage pressure vessel.

3.2. Automatic Water Level Controller. An automatic water level controller was installed at the dissolved carbon dioxide laden water outlet of scrubbing column unit. This maintained a constant water level. The water level was maintained between two points A and B with the help of a "magnetic reed switch type float sensor" and "On/Off type solenoid valve." The float ball of the sensor moved according to the water level. When water level reached above the point "A" sensor generates a "normally open" signal to open the solenoid valve and water flows out till the water level set value and 


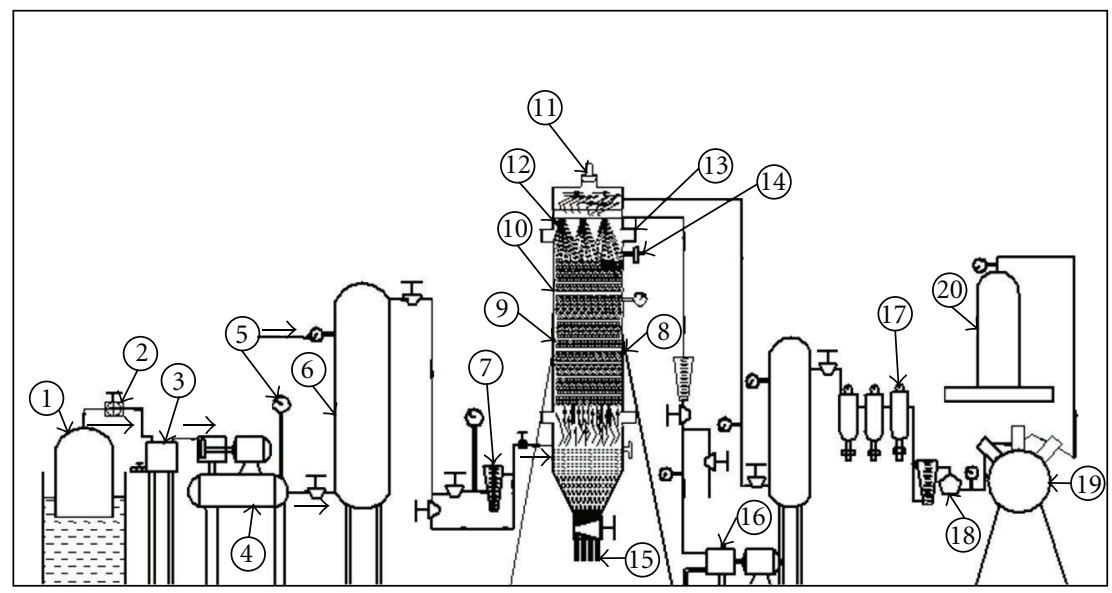

\begin{tabular}{lll}
\hline No. Description & No. Description & No. Description \\
\hline (1) Biogas plant & (2) Ball valve & (3) Water remover \\
(4) $\begin{array}{l}\text { Compressor mounted } \\
\text { with biogas receiver }\end{array}$ & (5) Pressure gauge & (6) Gas storage vessel \\
(7) Rotameter & (8) Supporting stand & (9) Reshching rings \\
(10) Scrubber & (11) Pressure safety valve & (12) Water sprayer \\
(13) Flange & (14) Water level view glass & (15) $\mathrm{CO}_{2}$ laden water outlet \\
(16) High pressure water & (17) Moisture removing & (18) Pressure reducer \\
(19) Three stage gas & filter &
\end{tabular}

FIGURE 1: Schematic diagram of water-scrubbing-based methane enrichment in biogas and compression system.

when the float ball reaches at point " $\mathrm{B}$ ", then it generates a "normally closed" signal to off the solenoid valve.

\subsection{Automatic Pressure Controller at Purified Gas Outlet} Stream. The automatic pressure controller setup installed at the outlet of purified biogas line was able to maintain a constant pressure range of $\sim 0.1$ to $1.0 \mathrm{MPa}$ at the outlet gas stream of the water scrubbing column unit. A differential pressure switch was configured to set the pressure value of 1.0 MPa and differential pressure value of $0.1 \mathrm{MPa}$. Therefore, when the pressure in the scrubbing column reached a value of 1.0 MPa, "pressure switch" generates open signal to the "solenoid valve," which further allowed the pneumatic source to open the "pneumatic ball valve" and released the gas to purified biogas storage vessel. As soon as the pressure in the scrubbing column unit decreased to a set value, "pressure switch" generates closes signal which closes the "solenoid valve" which further shuts off the "pneumatic ball valve" to stop the release of gas to purified biogas storage vessel. Thus, it had maintained constant pressure in the range of 0.9-1.0 MPa in water scrubbing column unit.

3.4. Working of the System. The raw biogas from a $20 \mathrm{~m}^{3} /$ day capacity floating drum type biogas plant fed with jatropha de-oiled seed cake was passed through a single-stage compressor after removing moisture and stored in a pressure vessel at more than 1.0 MPa. The compressed raw biogas of desired flow rate was fed to the scrubbing column unit through a rotameter. A nonreturn valve was provided in the line to prevent back flow of the fed raw biogas. Biogas and water flow rates were regulated through valves, and a counter flow of gas and water was maintained in a scrubbingcolumn unit. At bottom section of the scrubber column, water level was maintained up to half mark with help of an automatic water level controller. It acts as a water seal and prevents escape of compressed biogas from the bottom of the scrubbing column. Carbon dioxide absorbed water was discharged through outlet of the scrubbing column. The gas coming out (methane enriched biogas) from the top of the scrubbing column was stored in a pressure vessel for further compression and storage in CNG cylinders and analyzed for methane and carbon dioxide contents.

3.5. System Performance Parameters. The performance of improved water scrubbing system was evaluated in terms of percentage of carbon dioxide absorbed in water (i.e., performance index). Methane and carbon dioxide contents in raw biogas were $65 \%$ and $32 \%$, respectively. The effect of 


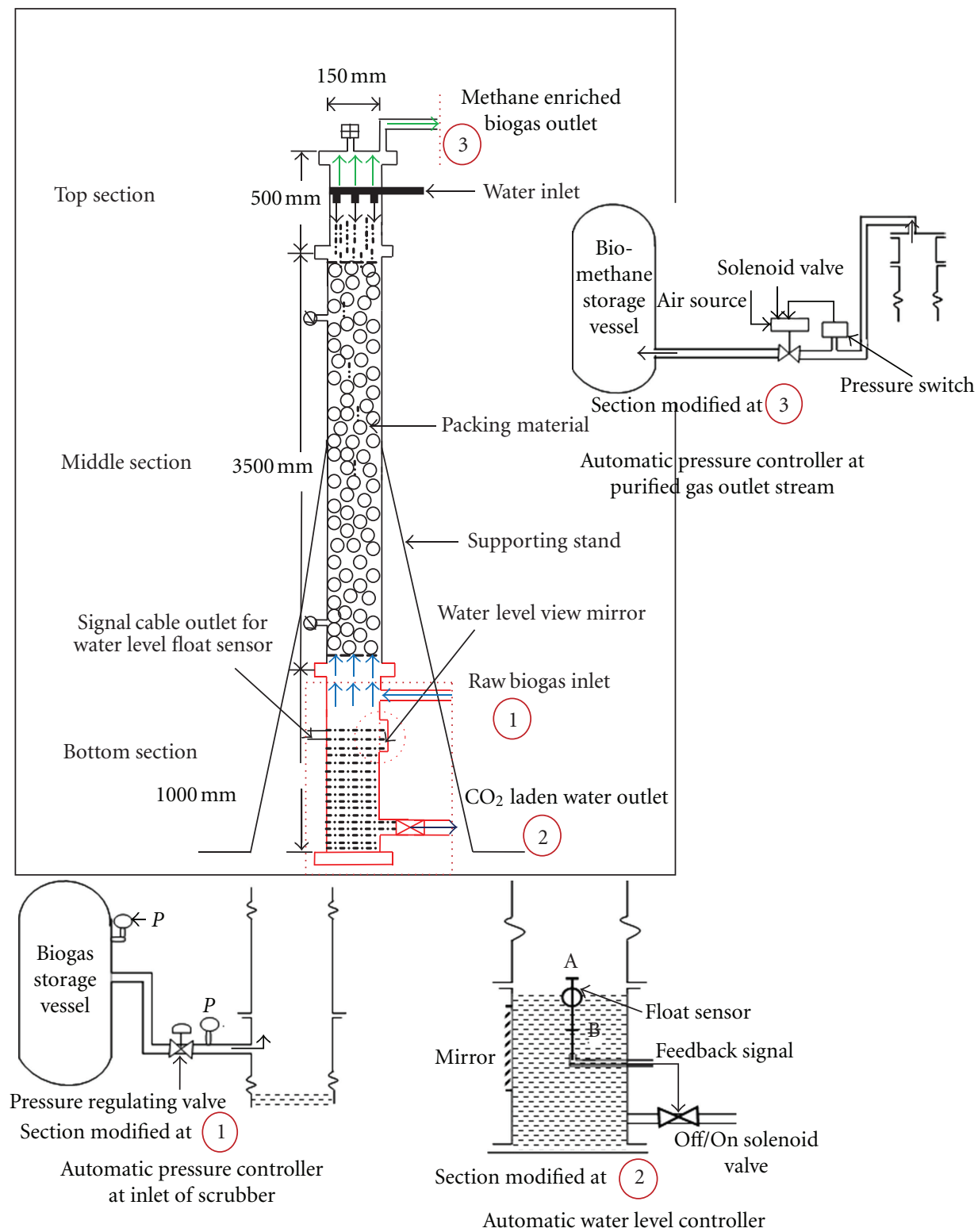

...... Automated sections of scrubbing column

FIGURE 2: Incorporated automatic control systems in packed bed absorption column of water scrubbing system.

column-operating pressure, in-flow rates of water and biogas on quality of methane enriched biogas was studied. The operating variables were column-operating pressure, biogas in-flow, rate and water in-flow rate and are shown in Table 2. The performance index was computed by using

$$
\sigma=\frac{\left(1-\left(y_{e} / y_{r}\right)\right)}{\left(1-\left(y_{e} / 100\right)\right)} \times 100
$$

where $\sigma$ is the performance index of scrubbing column, \%; $y_{e}$ is the volumetric content of carbon dioxide in methane enriched biogas, \%; $y_{r}$ is the volumetric content of carbon dioxide in raw biogas, $\%$.

\section{Results and Discussion}

Table 2 shows the observed values of carbon dioxide content in methane-enriched biogas obtained from the purified gas-stream of the scrubbing unit for $0.8 \mathrm{MPa}$ as well as 1.0 MPa operating column pressure.

Figures 3 and 4 depict the variation of the performance index with respect to biogas in-flow rate at column-operating pressure of 0.8 and $1.0 \mathrm{MPa}$, respectively. It is evident from Table 2 and Figure 3 that the value of performance index first increased then decreased with increase in biogas inflow rate at $0.8 \mathrm{MPa}$ column-operating pressure. The highest performance index of $92.3 \%$ was observed at $1.5 \mathrm{~m}^{3} / \mathrm{h}$ inflow rates of biogas as well as water. Similarly, the highest 
TABLE 2: Performance of automated water scrubbing system.

\begin{tabular}{|c|c|c|c|c|}
\hline $\begin{array}{l}\text { Column pressure, } \\
\mathrm{MPa}\end{array}$ & $\begin{array}{c}\text { Biogas in-flow rate, } \\
\mathrm{m}^{3} / \mathrm{h}\end{array}$ & $\begin{array}{l}\text { Water in-flow rate, } \\
\mathrm{m}^{3} / \mathrm{h}\end{array}$ & $\begin{array}{l}\mathrm{CO}_{2} \text { remained in } \\
\text { enriched biogas, } \%\end{array}$ & $\begin{array}{l}\text { Performance index } \\
\qquad(\sigma), \%\end{array}$ \\
\hline \multirow{5}{*}{0.8} & 1.0 & 1.5 & 5.0 & 88.8 \\
\hline & 1.5 & 1.5 & 3.5 & 92.3 \\
\hline & 2.0 & 1.5 & 4.0 & 91.1 \\
\hline & 2.5 & 1.5 & 6.5 & 85.2 \\
\hline & 3.0 & 2.0 & 8.5 & 80.3 \\
\hline \multirow{5}{*}{1.0} & 1.0 & 1.5 & 4.0 & 91.1 \\
\hline & 1.5 & 1.5 & 5.0 & 88.8 \\
\hline & 2.0 & 1.5 & 3.5 & 92.3 \\
\hline & 2.5 & 2.0 & 3.0 & 93.4 \\
\hline & 3.0 & 2.5 & 5.0 & 88.8 \\
\hline
\end{tabular}

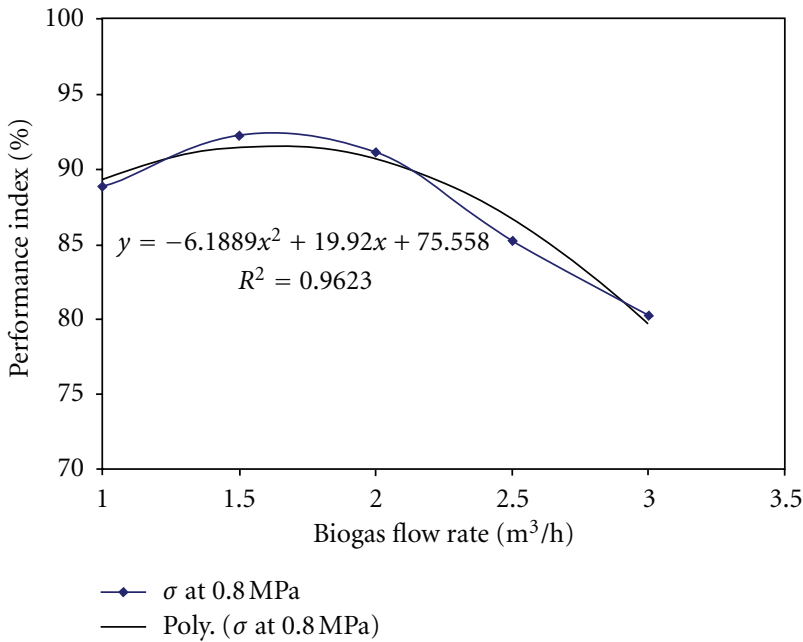

Figure 3: Effect of in-flow biogas rate on performance index at $0.8 \mathrm{MPa}$ column-operating pressure.

value of performance index was observed as $93.4 \%$ at biogas in-flow rate of $2.5 \mathrm{~m}^{3} / \mathrm{h}$ and water in-flow rate of $2.0 \mathrm{~m}^{3} / \mathrm{h}$ with the column-operating pressure of 1.0 MPa.

The observed results showed that the percentage absorption of carbon dioxide increases with increase in scrubbing column pressure for all biogas in-flow rates. The highest carbon dioxide absorption of $90.6 \%$ was observed at $1.0 \mathrm{MPa}$ column-operating pressure with a methane purity of $97 \%$ in purified gas outlet stream of the water-scrubbing system. The performance result of a $5.9 \mathrm{~kW}$ stationary diesel engine converted into spark ignition mode, run on compressed natural gas (CNG) and methane-enriched biogas (Bio-CNG) obtained from improved water scrubbing system, has showed that the engine performance is almost similar to that of compressed natural gas without any significant power loss [10].

\section{Conclusions}

The incorporation of automatic control systems in the water scrubbing unit has resulted into a steady state operation

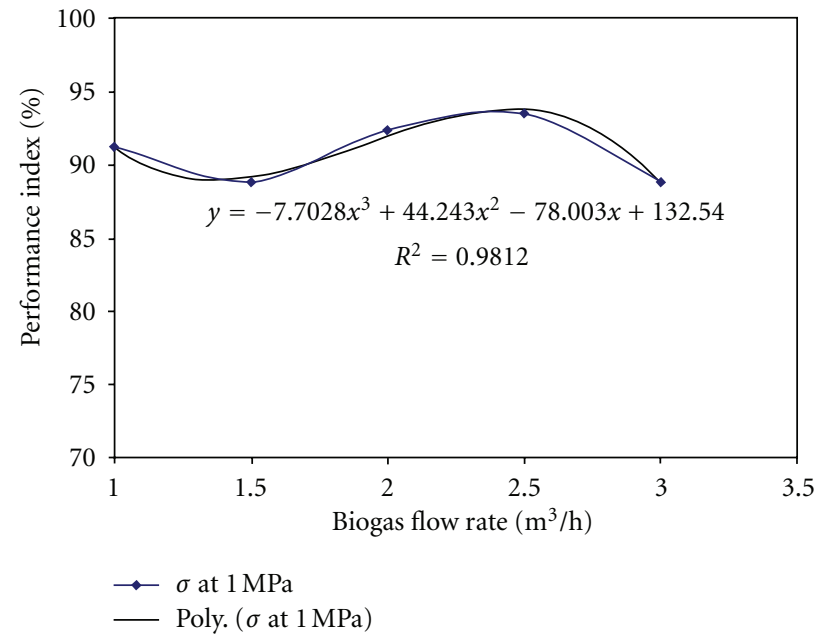

Figure 4: Effect of in-flow biogas rate on performance index at 1.0 MPa column-operating pressure.

of the system which had provided a consistent methane quality in the outlet stream of purified gas. The improved automated water scrubbing unit enriched the biogas up to $97 \%$ methane at $1.0 \mathrm{MPa}$ column-operating pressure with $2.5 \mathrm{~m}^{3} / \mathrm{h}$ biogas in-flow rate and $2.0 \mathrm{~m}^{3} / \mathrm{h}$ water inflow rate. The incorporated automation in the system was found extremely satisfactory. Furthermore, the installation of automatic controls in the system had resulted into a significant labour savings for efficient operation of the biogas enrichment system. Further, the methane-enriched biogas is a good gaseous fuel as good as natural gas, and also biogas is renewable and $\mathrm{CO}_{2}$ neutral fuel in terms of net emissions of carbon to the atmosphere.

\section{Acknowledgments}

The authors are highly thankful to Centre for Rural Development and Technology and Mechanical Engineering Department, Indian Institute of Technology Delhi, New Delhi, India, for providing necessary facilities, support, and financial funding to conduct this paper. 


\section{References}

[1] C. N. Hamelinck, G. Van Hooijdonk, and A. P. C. Faaij, "Ethanol from lignocellulosic biomass: techno-economic performance in short-, middle- and long-term," Biomass and Bioenergy, vol. 28, no. 4, pp. 384-410, 2005.

[2] Y. Sun and J. Cheng, "Hydrolysis of lignocellulosic materials for ethanol production: a review," Bioresource Technology, vol. 83 , no. 1, pp. 1-11, 2002.

[3] A. Hilkiah Igoni, M. J. Ayotamuno, C. L. Eze, S. O. T. Ogaji, and S. D. Probert, "Designs of anaerobic digesters for producing biogas from municipal solid-waste," Applied Energy, vol. 85, no. 6, pp. 430-438, 2008.

[4] A. Demirbas, "Political, economic and environmental impacts of biofuels: a review," Applied Energy, vol. 86, no. 1, pp. S108S117, 2009.

[5] S. S. Kapdi, V. K. Vijay, S. K. Rajesh, and R. Prasad, "Biogas scrubbing, compression and storage: perspective and prospectus in Indian context," Renewable Energy, vol. 30, no. 8, pp. 1195-1202, 2005.

[6] G. Nonhebel, Gas Purification Processes, George Newness, London, UK, 1964.

[7] J. Cebula, "Biogas purification by sorption techniques," Architecture Civil Engineering Environment, vol. 2, pp. 95-103, 2009.

[8] A. Petersson and A. Wellinger, "Biogas upgrading technologies-developments and innovations," IEA Bioenergy, Task 37-Energy from biogas and landfill gas, 2009, http://www.ieabiogas.net.

[9] K. Ken, A. Don, J. P. Batmale, B. John, R. Brad, and S. Dara, "Biomethane from dairy waste-a sourcebook for the production and use of renewable natural gas in California," 2005.

[10] R. Chandra, V. K. Vijay, P. M. V. Subbarao, and T. K. Khura, "Performance evaluation of a constant speed IC engine on CNG, methane enriched biogas and biogas," Applied Energy, vol. 88, no. 11, pp. 3969-3977, 2011. 

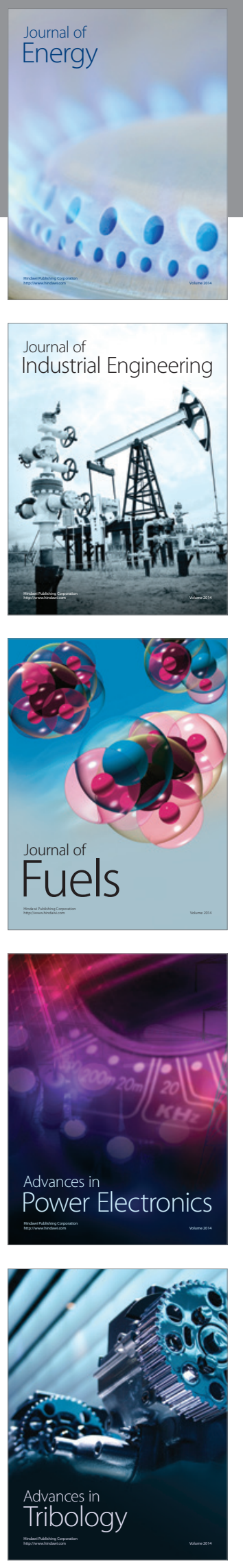
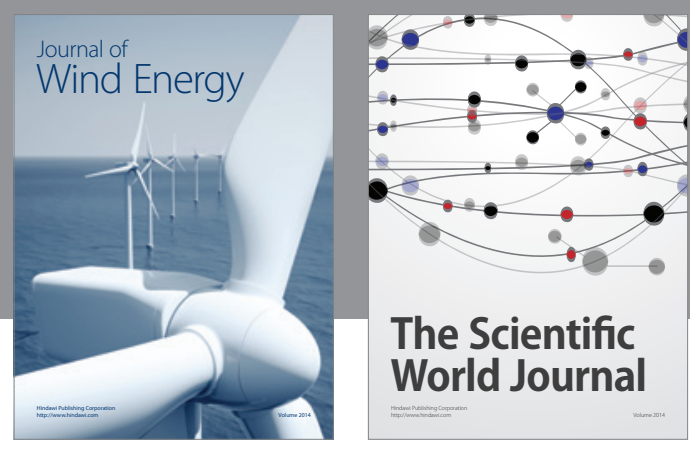

The Scientific World Journal

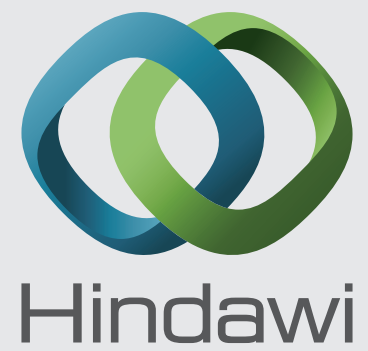

Submit your manuscripts at http://www.hindawi.com
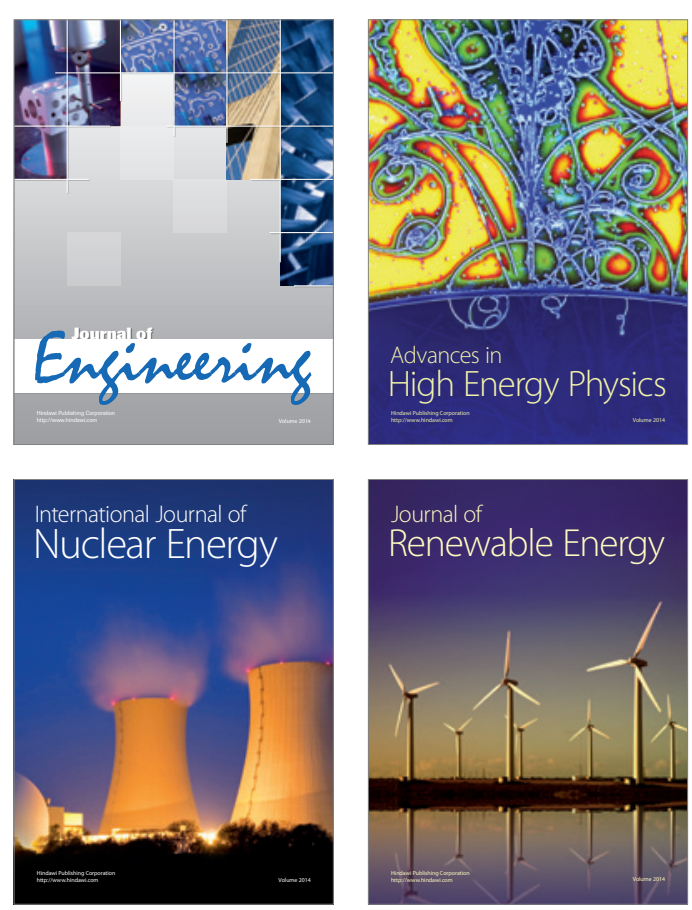

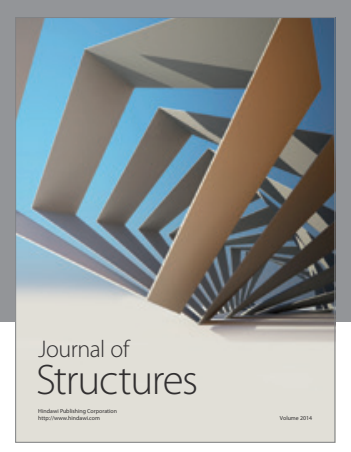

Rotating
Mechinery
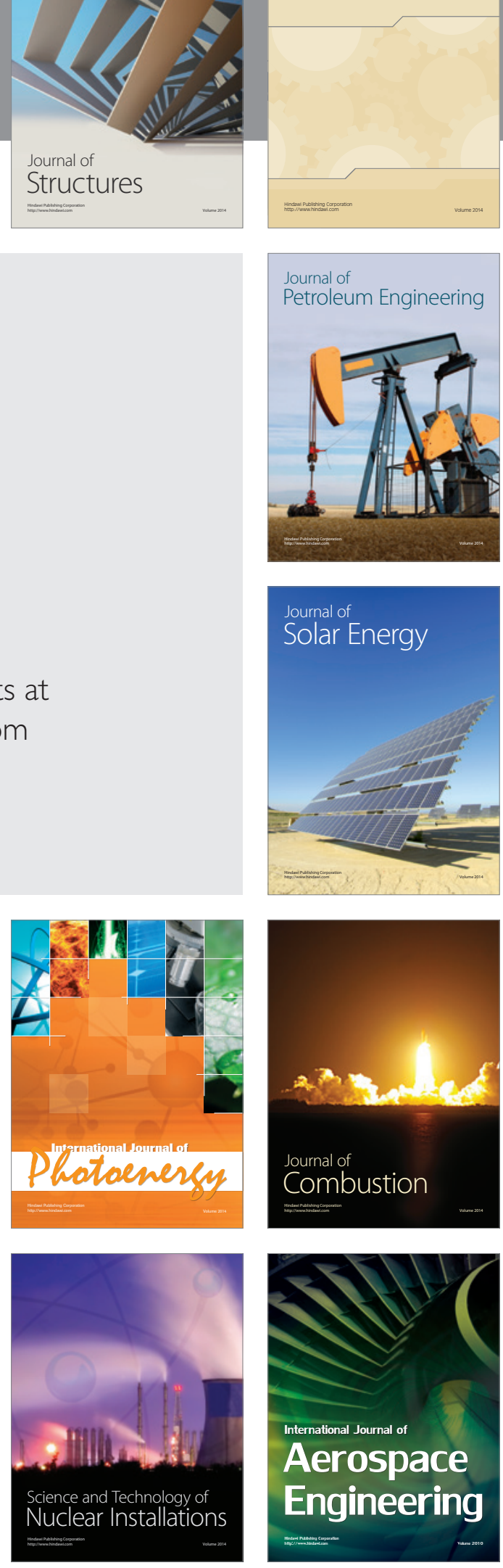